\title{
Preventive Medicine
}

\section{Scandinavian and Dutch lessons in childhood road traffic accident prevention}

\author{
J G AVERY，P J AVERY
}

\begin{abstract}
"They're funny things, Accidents. You never have them till you're having them."-Eeyore to Christopher Robin in The House at Pooh Corner, A A MILNE.
\end{abstract}

The tragic loss of life in children resulting from road traffic accidents has caused concern for some years now in northern Europe. The problem becomes even more pressing when we realise that road traffic accidents are the most severe form of accident experienced by children in developed countries. It is made even more acute when we consider the consequences for some children in the form of serious permanent disability such as brain damage or limb deformity.

In April 1981 we made a study tour of Sweden, Norway, Denmark, and Holland. We chose to visit these countries because of the unique contribution that each has made in one way or another in childhood accident prevention. We had discussions with numerous experts, visited several centres of excellence, and observed safety in action in the street, on housing estates, and in schools. We could not help but be impressed by the realistic and pragmatic approach that has been taken by several different authorities to this important problem of child health. We were particularly impressed by several measures being taken to prevent road traffic accidents.

In Britain many similar approaches have been made and in some cases we have been in the forefront. Nevertheless, there are many areas where additional action has been effectively taken in Scandinavia and in Holland and where lessons may be learnt for the benefit of further reducing childhood accidents and their severity in Britain.

Much can still be done to modify the environment, to improve safety precautions, and to teach parents and children about accident prevention without in any way inhibiting a child's natural exploratory instincts and need for play. It is perhaps easier to appreciate the magnitude and perspective of the problem when we realise that "the child lives in an adult world designed by adults for adults"' and that "the road is the most complicated environment a child can experience in his everyday life." ${ }_{2}$

In most European countries the greatest risk of a serious or fatal accident in childhood is in the form of a road traffic accident. The risks vary from country to country by mode of transport and by age and sex but overall the risks as a pedestrian are greater than those as a cyclist, which in turn are greater than those as a car occupant. The younger the child the greater the risk as a pedestrian and the older the child the greater the risk as a cyclist.

South Warwickshire Health Authority, Warwick CV34 4DE

J G AVERY, MD, FFCM, district medical officer

Harbury, Warwickshire

P J AVERY, State-registered nurse
The risks in traffic are greater than in any other activity. In Norway, for example, the overall risks in traffic for all ages have been shown to be higher than those in the more dangerous occupations such as fishing, mining, and forestry when measured per hour of exposure. ${ }^{3}$ These risks are particularly high for the very young and very old.

In recent years there have been changes in road traffic accident death and injury rates in Scandinavia and Holland with, in general, a fall in injuries to pedestrians and cyclists but slight rises in injuries to car occupants.

\section{Safety of pedestrians}

The major efforts made towards the safety of pedestrians have been in a complete redesign of the town centre and housing estate environment. This is seen in all of the countries with the development of pedestrian precincts in cities and towns. It is seen at its best in both old and new housing areas with the widespread use of the "living street" or woonerf concept, especially in Holland and Sweden (fig 1). The theory is to achieve a total integration of all the users of the street environment but without causing major conflict between any of them. The placing of obstacles such as "sleeping policemen" and physical barriers in the way of cars slows down traffic considerably and allows cyclists and pedestrians much greater freedom. The provision of play areas and playground equipment allows children to play freely in the street but not actually in fast moving traffic.

The Norwegians are showing increasing concern for the plight of the urban child who is sometimes so frightened to go outside that he misses all the joys of play and the appreciation of nature so essential to his healthy development. A redesign of housing, shopping, and amenities complexes so that a child may proceed from home to school and playground without coming into serious conflict with traffic is the most effective way of ameliorating this problem.

It is difficult to evaluate the effectiveness of these newer concepts in urban design but studies in Gothenburg claim this to be a particularly effective method of reducing pedestrian accidents. The risk for pedestrians and cyclists in newer areas with separated traffic is $5-10$ times lower than in older areas with mixed traffic. ${ }^{4}$ By following the principles of urban planning laid down in the "SCAFT" Guidelines ${ }^{5}$ much can be achieved.

\section{Safety of cyclists}

Bicycle accidents are the major reason for attendance by children at hospital as a result of a road traffic accident in all of the countries visited.* In Sweden certain designs of "high rise"

* Cycle accidents are the major reason for attendance but pedestrian accidents are the major cause of fatal and serious injury. 

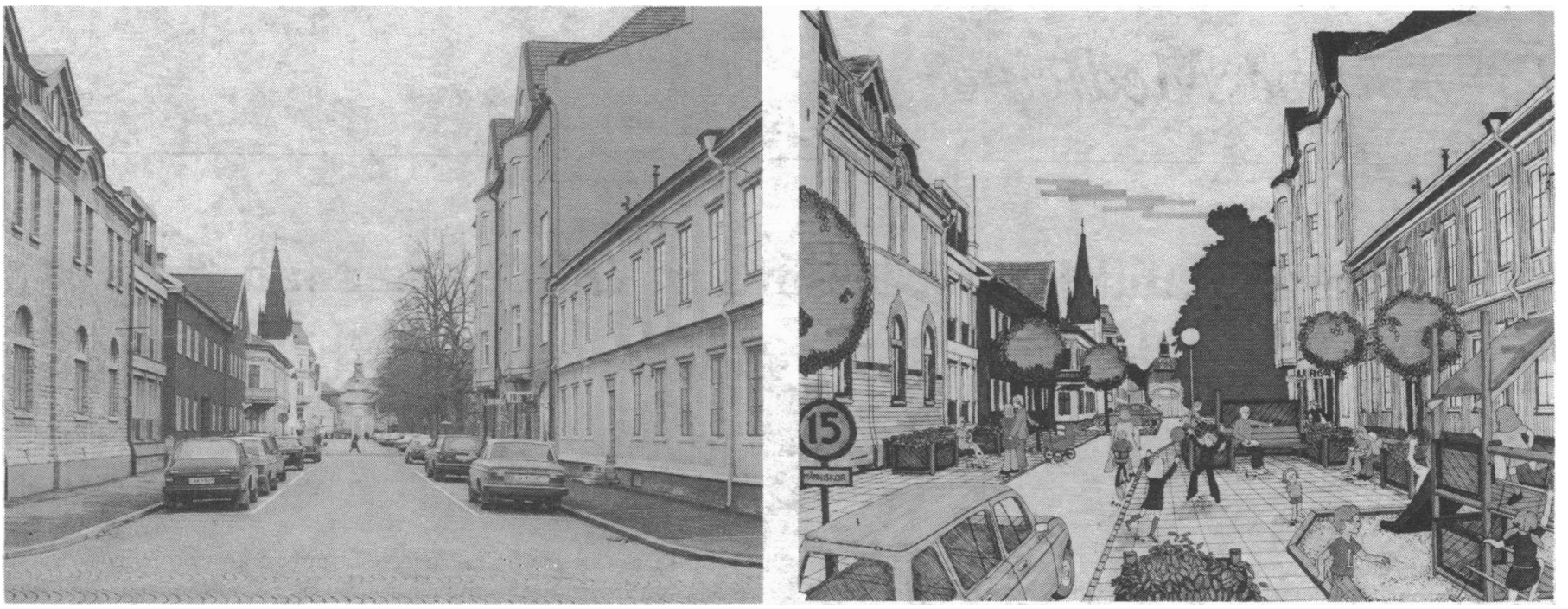

FIG 1-The living street or woonerf concept of urban design-before and after.

bicycle (fig 2) have now been banned as being too difficult for children to control safely. ${ }^{6}$ Experiments are currently being carried out by the National Road and Traffic Research Institute at Linköping on braking systems on bicycles. Preliminary work has shown that small children particularly often do not have the strength and co-ordination to work the rear wheel foot brakes typically used in Sweden. Other studies ${ }^{7}$ have shown that most children aged 8 are still not fit to cycle in traffic alone and are only really fully competent by around 13 .

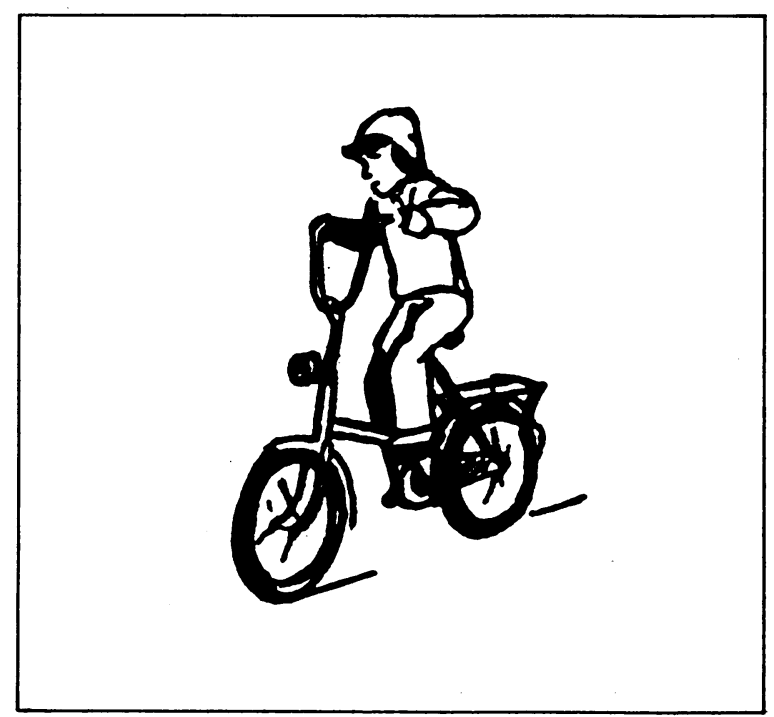

FIG 2-"High-rise" bicycle."

In Sweden, Denmark, and Holland considerable progress has now been made in providing cycleways in both rural and town areas. The cyclist is a recognised road user and is given due consideration in the design of road junctions. Most cyclists carry prominent side and rear reflectors on their bicycles, and quite a few cyclists wear crash helmets (fig 3). The carriage of small children on the rear of the cycle is made both easy and safe by using carefully designed plastic seats with seat belts and foot protection (fig 4).

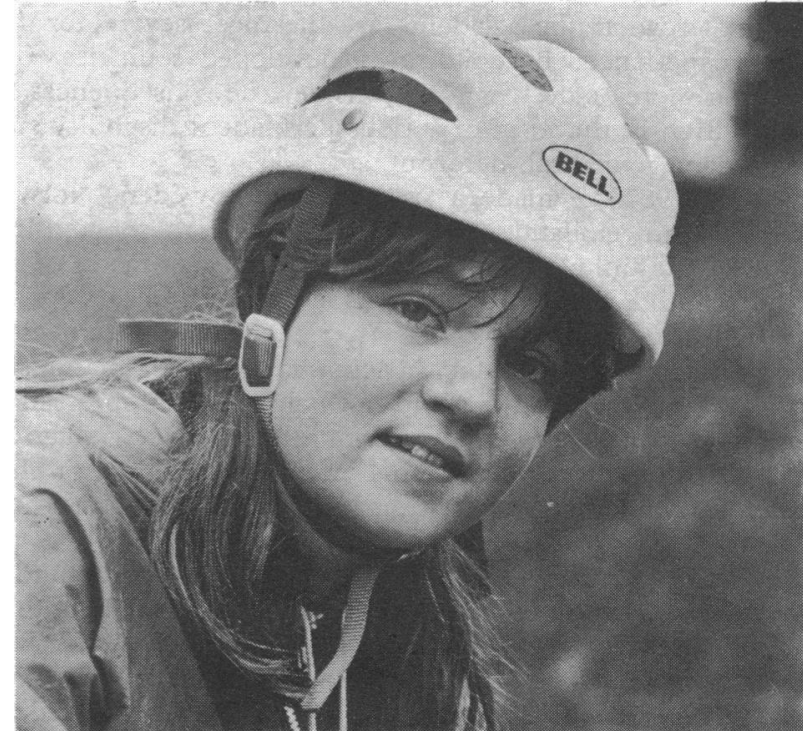

FIG 3-Cycle crash helmet. (By courtesy of Akta, Stockholm.)

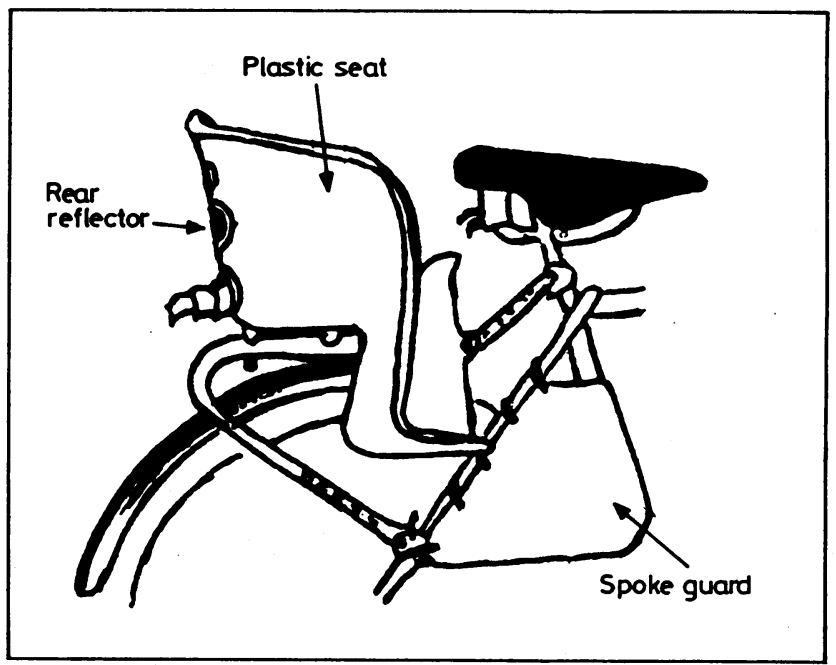

FIG 4-Rear child carrier for bicycle. 


\section{Safety of car occupants}

In each of the countries it is illegal to carry a child unrestrained in the front seat of a motor-car. None yet requires a child to be restrained in the rear, but considerable publicity has been given to the safe carriage of children in motor-cars. Road safety experts in Sweden consider that the safest place to carry a baby is in a carry-cot on a bench in the rear $^{8}$ (fig 5). The safest place for a toddler is in a rearward facing bucket-seat placed in the front or rear. ${ }^{9}$ The safest place for a younger child is in an adult belt or child harness using a booster cushion ${ }^{10}$ in the rear seat, while an older child may be quite safely restrained in an adult belt alone.

Older children in the rear using adult seat belts (and booster cushions) sustain $50 \%$ fewer injuries than children travelling unrestrained." ${ }^{11}$ The greatest injury-reducing effect of all is on injuries to the head.

In Sweden around $80 \%$ of children aged 1-4 are restrained when being carried in cars. Most of these are in rearward-facing bucket seats in the front compartment of the car. Studies carried out by both Volvo ${ }^{8}$ and the National Road and Traffic Research Institute ${ }^{912}$ have shown that rearward facing seats give the child the best protection and also offer excellent opportunities for supervision by the driver. In all Nordic countries and in Holland the law requires the adult occupants of front seats to wear seat belts.

Many British road safety experts do not favour the rearward facing seat. The widely recommended British view is for a baby up to 9 months to be strapped in on the back seat in a carry cot, for a toddler from 9 months to 4 or 5 years to be in a bucket seat with harness in the rear, and for a child from 4 or 5 to around 11 or 12 to be in an ordinary harness in the rear. In recent months child booster cushions have come on to the market in Britain. Probably this new method, which has been well tried in Sweden and Australia, will now gain greater acceptance in Britain. The great advantages of the booster cushion are that it may be used with an adult lap and diagonal belt in the front or rear, it may be used over a wide age range (certainly from 4 to 12 and possibly even from 1 year), and it gives the child raised visibility. We know from our own experience that young children love to use booster cushions-it is very much "one up" over their friends.

\section{Road safety education and training}

Sweden has pioneered several efforts in road safety training. ${ }^{2}$ Evaluation of this work has shown that children's knowledge of road safety can be greatly improved when the instruction is restricted to certain basic skills with practical lessons in a real traffic environment. ${ }^{13} 14$ This is better than a traffic simulator, which in turn is better than the classroom. Nevertheless, despite this training and improved knowledge it cannot in any way be guaranteed that children will always be reliable road users, especially as some parents tend to overestimate the child's ability to cope with the hazards of traffic. Most children show an absorbing interest in learning correct traffic behaviour and most are anxious to obey the traffic rules despite the bad example sometimes set by parents. Children need not only protection from the hazards but also the best possible safety education from the beginning of their lives.

The importance of a knowledge of child development in relation to the ability of a child to cross a road or ride a bicycle has been fully recognised in the pioneering work of Stina Sandels ${ }^{2}$ and Kerstin Bäckström ${ }^{14}$ in Stockholm. A child has many "handicaps" when compared with a mature and healthy adult. The child has a lower eye level, cannot process complicated data so quickly, and cannot readily appreciate speed and danger. He may not be able to distinguish the direction of a sound and may well be distracted, especially by a friend across the road. This all means that a child cannot cross the road alone with any degree of safety until the age of 8 or 9 or ride a bicycle competently until $13 .{ }^{7} \mathrm{~A}$ child needs to learn a little at a time but can learn by repeated experience, ideally supervised out of doors in the real traffic environment wherever possible.

Norway has also undertaken several pioneering activities in education for survival. These include participation in a children's traffic club, whose facilities are offered by mail to the parents of all children aged 3 and over. Some $30 \%$ participate in a course which costs around $£ 5$ for the mailing of materials every six months until the child enters school at the age of 7 . An evaluation of the club ${ }^{15}$ has found that it does contribute towards improving the child's road safety through greater knowledge and through a lowering of the accident rate. This was in spite of the observation that the actual behaviour of the trained children was no different from that of the untrained.

Denmark-Among several activities children receive a total of 48 hours of compulsory training in road safety between their first and ninth year. In addition children in their fourth and fifth years may participate in a voluntary scheme using a simulated road environment in selected schools. There is a contact teacher in each school, and local police and parents also participate in the training. An early learning programme (similar to the Norwegian Children's Traffic Club) is also available.

Holland has also taken a great interest for several years in road safety education for young road users. Research carried out at the University of Gröningen has shown that classroom education is only of limited value and that reasonable factual knowledge
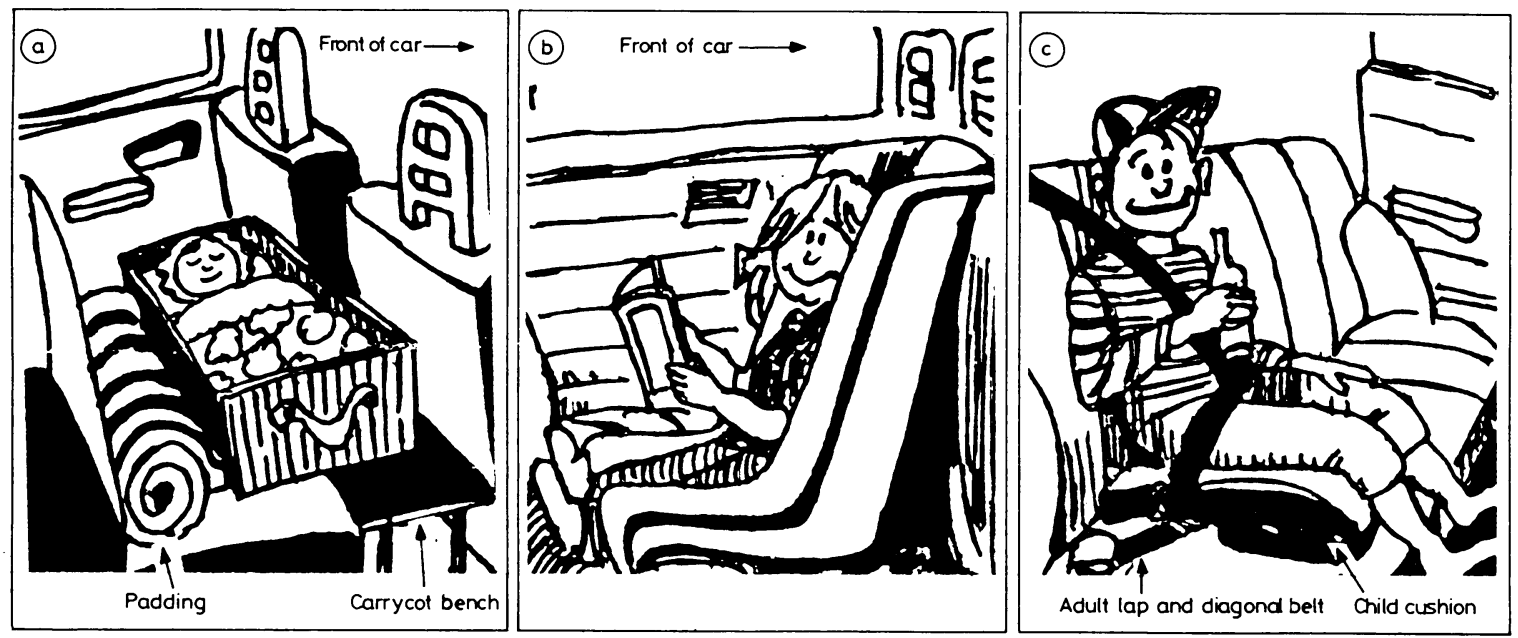

FIG 5-Latest Volvo solutions for the safety of children in cars. (a) Up to 9 months-carrycot; (b) 10 months-6 years-bucket seat with harness; and (c) 7-10 years-adult belt and booster cushion. (By courtesy of Volvo.) 
need not necessarily be translated into the right behaviour for the traffic circumstances. ${ }^{16}$ The simulated road environment in the form of a "traffic garden" is also used, but some critics argue that this play environment is only likely to engender a less than serious approach to real traffic problems. The current Dutch view is that environmental improvement will do more to reduce road traffic accidents to children than education. ${ }^{17}$

\section{Have the efforts been successful?}

The only comparison that can readily be made between countries is of death rates, since these figures are the only ones published in the official WHO Statistics Annuals. Comparison between any form of morbidity measurement is limited due to variations in clinical practice as well as in recording and reporting of accident data. Mortality is only the "tip of the iceberg" of the broad range of childhood accidents. It is also biased towards accidents such as road traffic accidents and drowning, which are more likely to end up as a fatality. Changes in nomenclature and classification of accidents may also have some influence on trends when the figures are taken direct from WHO sources rather than from the more detailed national sources. Despite the well-recognised difficulties, we have analysed recent changes in childhood mortality from accidents in Scandinavia, Holland, and England and Wales. These have been compared to assess whether the efforts made by these countries have been successful.

During 1962-78, Sweden showed the greatest percentage fall in accident death rates of the five countries studied. The main reasons for these falls are seen in figs 6 and 7 covering 1960-74. The greatest fall in boys was seen in the rates due to drowning particularly in the very young, but good rates of fall were also seen in pedestrian and cyclist fatalities, again especially in the younger age groups.

The success of Swedish efforts at accident prevention in children is shown in the relatively lower percentage of all deaths to children occupied by accidents compared with all the other countries except England and Wales (fig 8). The latter has lower percentages due partly to its own success in reducing childhood accidents but also to its greater proportion of deaths due to other causes especially in the 1-4 age group.

Success in reducing road traffic accidents in Sweden also shows up in lower rates due to road traffic accident deaths than all other countries in the 1-4 age group and all except England

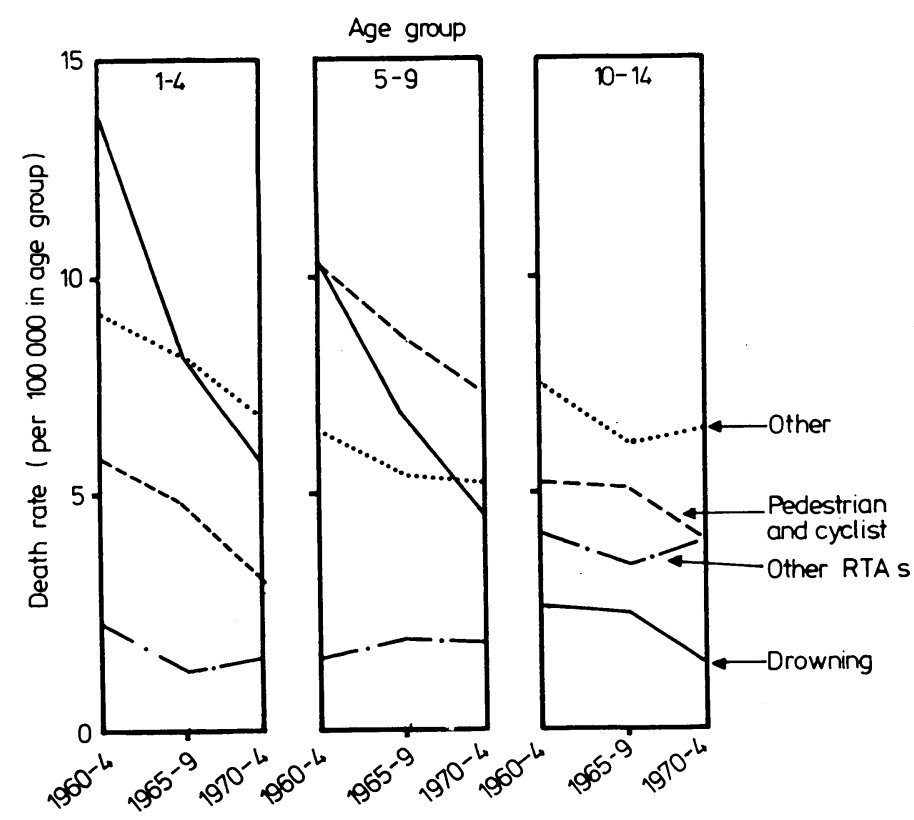

FIG 6-Death rates due to accidents for boys in Sweden, 1960-74.

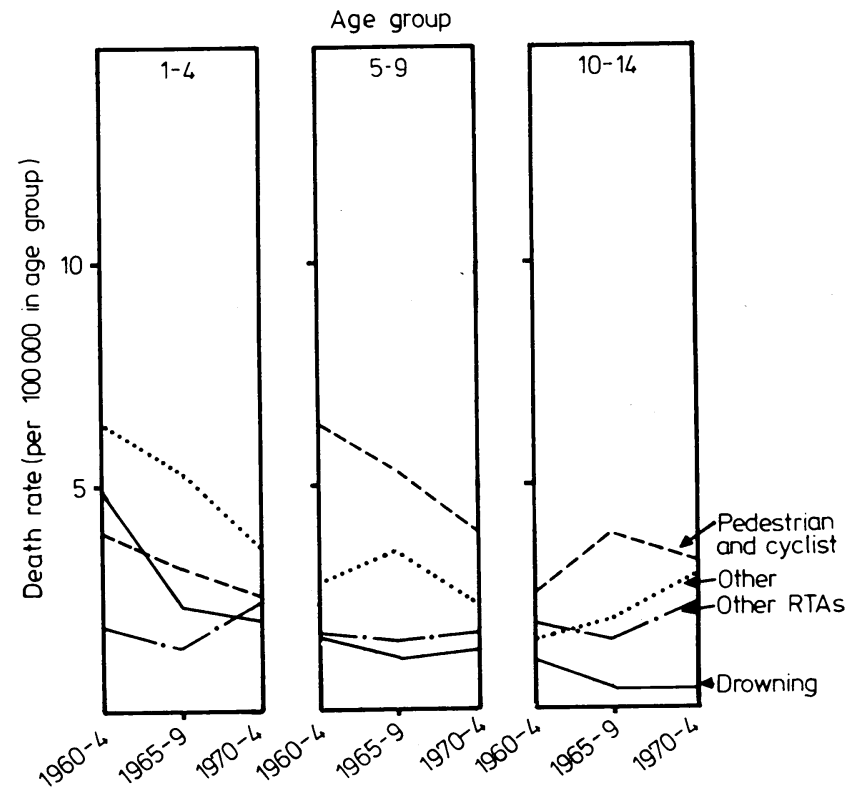

FIG 7-Death rates due to accidents for girls in Sweden, 1960-74.4

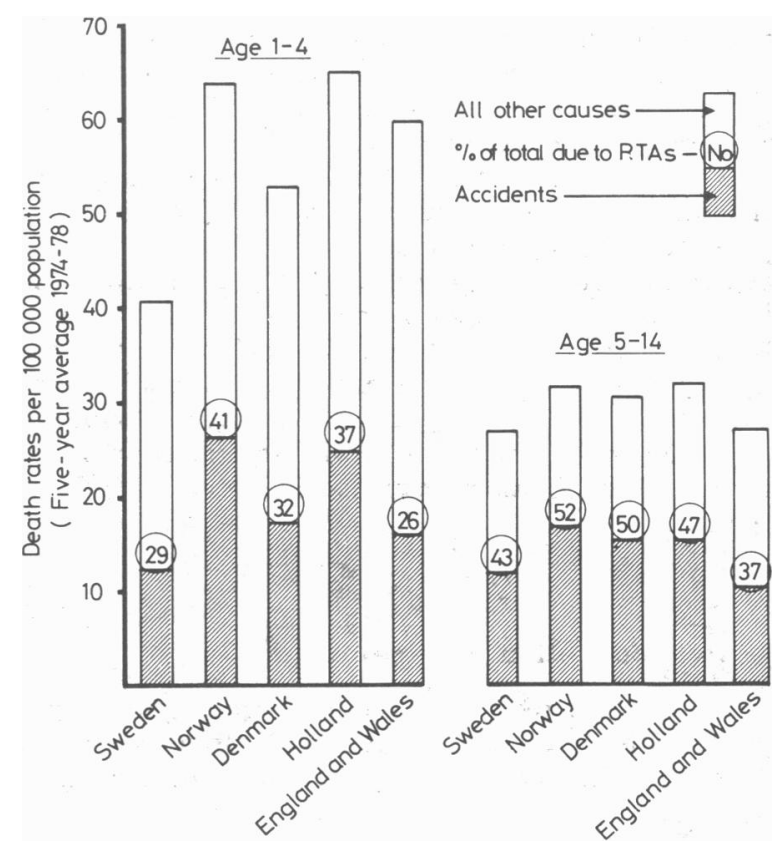

FIG 8-Relative importance of accidents as a cause of death in children in selected countries, 1974-8. In the $0-1$ age group accidents contribute only around $1-4 \%$ of all deaths (varies from country to country).

and Wales in the 5-14 age group (fig 9). The rate in the 0-1 group is higher probably due to the greater carriage of babies in cars and on bicycles.

Norway has also seen a steady fall in the death rate due to accidents in all child age groups. After remaining static or even rising for some years these figures have shown a pronounced fall since the early 1970 s, most noticeably in the younger age groups (figs 10,11, 12). The improvements in road traffic accident fatalities have been seen most noticeably in pedestrians in the 0-7 age group. These followed the introduction of traffic control schemes, improved urban design, and strict speed limits in residential areas. Tighter speed restrictions were also brought into the rural areas, where the most severe accidents occur. There were also improvements in the teaching of road safety in most of Norway. All these measures resulted between 1970 and 1978 in a $50 \%$ fall in the rate for deaths and serious injuries for 


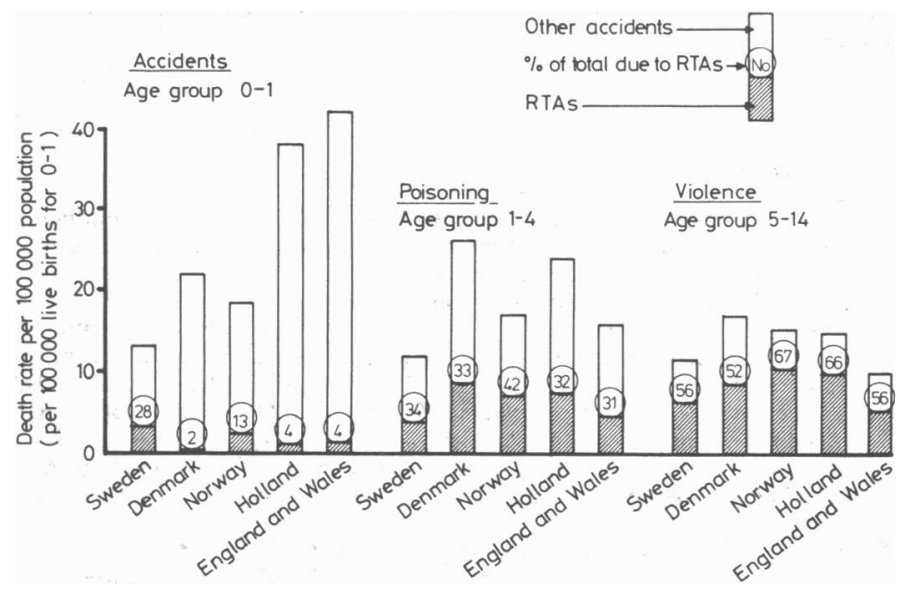

FIG 9-Death rates for accidents, poisoning, and violence in children aged $0-14$ in selected countries. (Five-year average for 1974-8.)

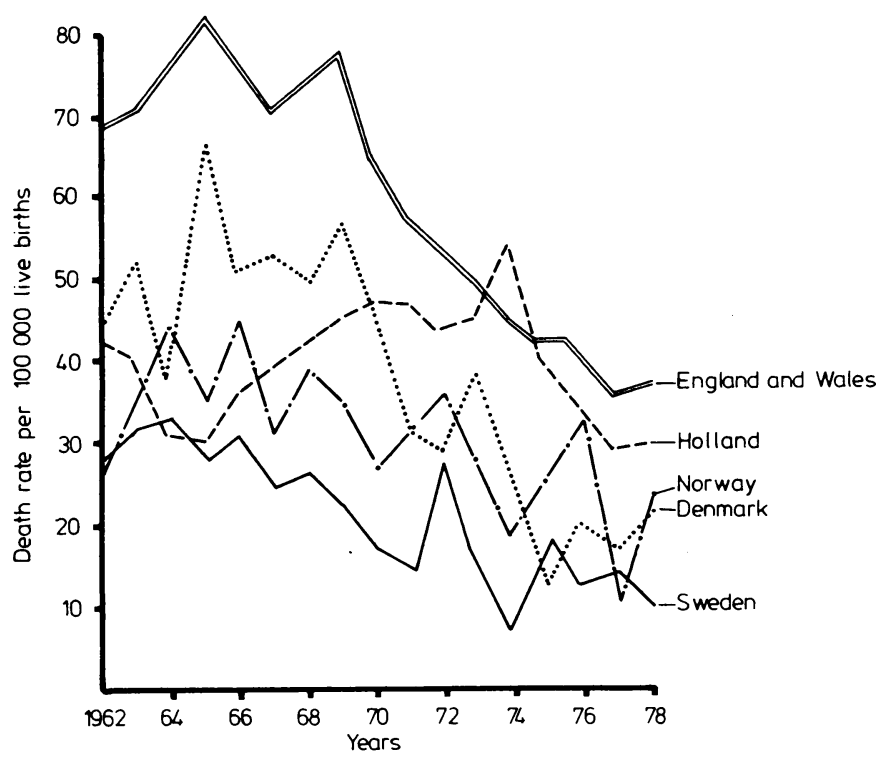

FIG 10-Death rates for accidents, poisoning, and violence in children aged $0-1$ in selected countries, $1962-78$.

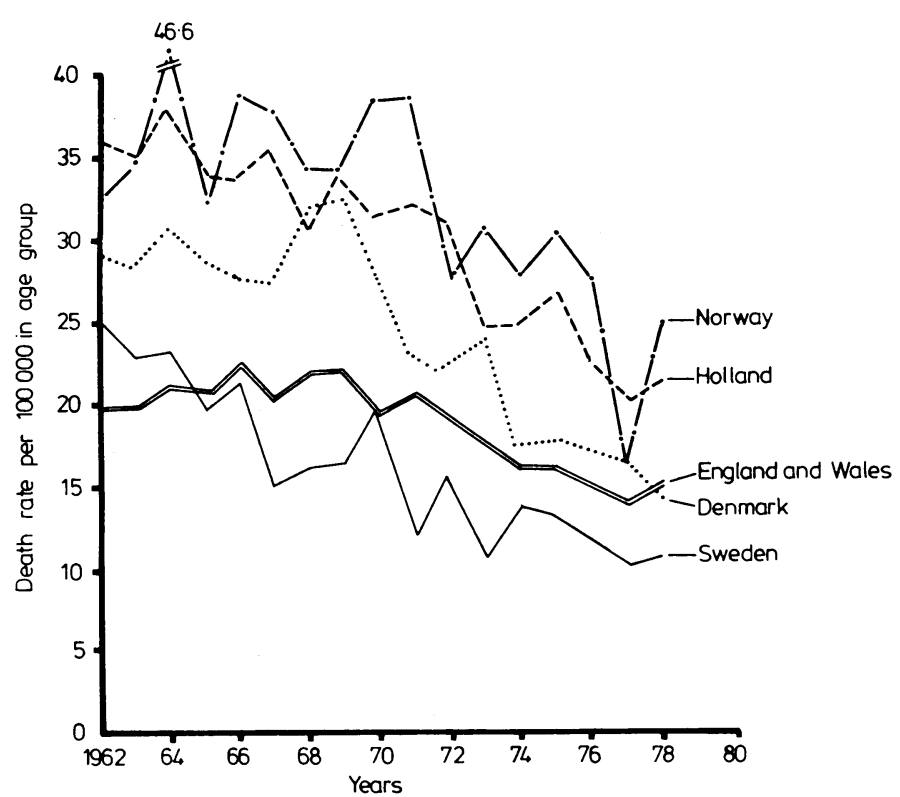

FIG 11-Death rates for accidents, poisoning, and violence in children aged 1-4 in selected countries, 1962-78.

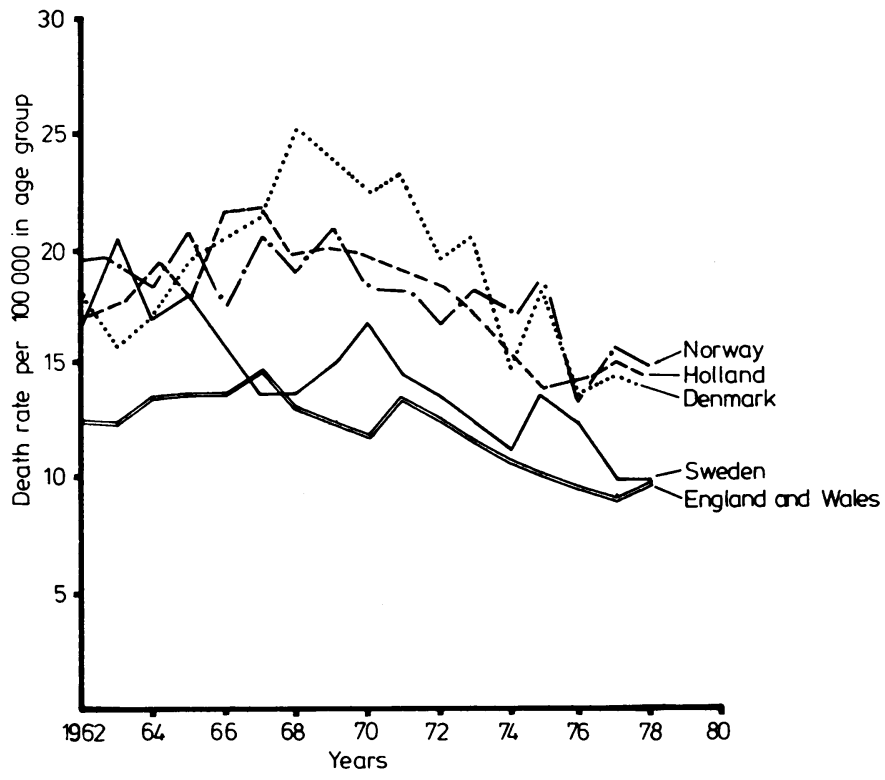

FIG 12-Death rates for accidents, poisoning, and violence in children aged $5-14$ in selected countries, $1962-78$.

pedestrians aged $0-7 .{ }^{18}$ Such dramatic changes were not seen in any other age group or class of accident although a fall of around $33 \%$ was seen in the $8-14$ pedestrian group during the same period.

During 1962-78 Denmark experienced first of all a rise and then a pronounced fall in death rates due to accidents in all ages of childhood. In the early 1970s the mortality due to traffic accidents among the children of Denmark was one of the highest in Europe. ${ }^{19}$ The dramatic fall that followed was the result of action along several fronts including improved road safety training. Perhaps the most significant effect was the effort made in both town and country to separate conflict between pedestrians and cyclists and the motorised road users.

In Holland the trends in death rates due to accidents in children have been a little different from those in the other countries. Death rates in each age group either rose or remained static until the early 1970s. After this a dramatic fall was experienced, mainly due to improvements in road traffic accident death rates especially in deaths to pedestrians and cyclists.

We have also reviewed the data for England and Wales, since one of the objectives of our visit was to see how our own country compared with the countries visited. Overall, England and Wales compare favourably with the other countries, particularly in rates for the older children (fig 12). An anomaly is the performance in the 0-1 group where England and Wales have long had higher rates than the other countries (fig 10). Despite this there has been a dramatic fall since 1969 , although even now the death rate in the 0-1 group is still well over twice that in Sweden. In the 1-4 age group England and Wales started off with the lowest death rate in 1962, remained static for several years, and only showed a slow decline from 1969 onwards (fig 11). Sweden with a more spectacular fall from 1962 onwards soon surpassed England and Wales and had rates well below these countries by the end of the 1970s.

The best performance by England and Wales has undoubtedly been in the 5-14 age group, where the death rates were slightly better than Sweden for several years. Even here the rate in England and Wales remained nearly static between 1962 and 1971 and only then showed a gradual decline. It could be argued that for the 1-4 and 5-14 age groups the other countries are only just catching up with improvements that were already made in England and Wales some years ago. Anyone familiar with the problem of accidents in childhood will realise that there is still ample room for improvement in performance in England and 
Wales. Large social class differences still remain with children at the more socially deprived end of the scale having death rates from accidents up to five times greater than those at the more privileged end. ${ }^{20}$

If a really worthwhile comparison is to be made of success in accident prevention in various countries account must be taken not only of mortality but also of morbidity. Even if there are difficulties in making comparisons of morbidity it should be possible to make some progress in the future by measuring in a standard way, for example, the long-term disability after accidents. Meanwhile the steady decline in death rates due to accidents in children must be seen as an encouraging sign to those who sometimes think that their efforts are in vain.

The mortality data show that Britain has made steady progress in childhood accident prevention and that our record stands up well in international comparisons. There are certain areas of childhood safety where we have not been as diligent as we might have been. These include safety for pedestrians (one of the worst records in Europe), cyclists (numerous head injuries and serious fractures), and children in cars (only about $15 \%$ travel with any form of restraint).

Some might argue that the price the Scandinavians and the Dutch pay for improvements in safety is a sanitated, regulated, and over-legislated society. Not too many people in those countries would see it that way but rather as a sensible and rational attempt to reduce what is, after all, a major tragedy when a serious accident befalls a child. We can surely learn some of the lessons that the Nordic countries and Holland have for us and still allow our children every possible opportunity to explore things, to play, and to enjoy their all too short childhood to the full.

We wish to express our gratitude for the considerable help and friendship that we found in all of the places visited. We would also like to thank the Coventry and Warwickshire Hospital Saturday Fund for their generous provision of a travelling fellowship to one of us (JGA) to allow this study tour to be carried out.

\section{People and places visited}

\section{SWEDEN}

Gothenburg: Dr J Nathorst Westfelt, Östra Sjukhuset; Professor L Köhler, Nordic School of Public Health; Dr Ove Lindgren, Chalmers University; $\mathrm{Mr} \mathrm{H}$ Norin, Volvo, AB; Linköping: Dr T Turbell and Mr C A Öström, National Swedish Road and Transport Research Institute; Stockholm: Mr Lars-Âke Lundquist, Children's Council; Ms Katarina Danielsson, Swedish Consumers' Institute; Ms IngaLill Söderquist, Tyresö Community; Uppsala: Professor Ragnar Berfenstam, Uppsala University.

\section{NORWAY}

Oslo: Mr S Røed Larsen and Ms Rita Jonsson, Ministry of Consumer Affairs and Government Administration; Ms $\mathrm{K}$ Berard-Andersen, Transport Economics; Mr Finn Larsstuen and Ms Sidsel Sandelien, Public Roads Administration; Dr Jens Steen, Health Council; Mr Johan Lund, Consumer Research; Mr Georg Wathne, Trygg Trafikk; Tonsberg: Dr Wollebaek, District Hospital.

\section{DENMARK}

Odense: Dr E Nordentoft, Dr R Somers, Mr T Kruse, and Mr K S Hansen, Odense University Hospital; Copenhagen: Professor B Sørensen, Hvidovre Hospital; Dr Dahl and Ms Randi Uldall, National Prevention Council, Ministry of the Interior.

\section{HOLLAND}

Delft: Mr J C Bastiaanse, Research Institute for Road Vehicles; Voorburg: Mr L T B van Kampen and Mr H van den Colk, Institute for Road Safety Research; Den Haag: Ms Irma de Boer, Traffic Training School.

\section{References}

${ }^{1}$ Berfenstam R. The work of the Swedish joint committee for childhood accident prevention. In: Jackson RH, ed. Children, the environment and accidents. Tunbridge: Pitman Medical, 1977.

2 Sandels S. Children in traffic. London: Elek, 1975.

${ }^{3}$ Hvoslef $\mathrm{H}$. Road user casualty risks in urban traffic. Oslo: Institute of Transport Economics, 1980. (In Norwegian with English summary.)

4 Gunnarsson SO. In: Berfenstam R, Gustafsson LH, Petersson O, eds Prevention of accidents in childhood. Uppsala: Department of Social Medicine, University Hospital, 1977.

5 SCAFT guidelines. Principles for urban planning with respect to road safety. Stockholm: National Board of Urban Planning, 1968. (Publication No 5.)

${ }^{6}$ Arnberg PW, Tydén T. Stability and manoeuvrability performance of different types of bicycles. Linköping: National Road and Traffic Research Institute, 1974. (Report No 45A.)

${ }^{7}$ Arnberg PW, Ohlsson E, Westerberg A, Öström CA. The ability of preschool and school children to manouvre their bicycles. Linköping: National Road and Traffic Research Institute, 1978. (Report No 194A.)

8 Norin H, Saretok E, Jonasson K, Samuelsson S. The child in the Volvo car. Gothenburg: AB Volvo Car Division, 1978.

${ }^{9}$ Arnberg PW. The design and effect of child restraint systems in vehicles. Ergonomics 1978;21.9:681-90.

10 Arnberg PW, Håkansson I. The child support seat. Linköping: National Road and Traffic Research Institute, 1980. (Report No 195.) (In Swedish with summary in English.)

11 Norin H, Nilsson-Emle A, Saretok E, Tingvall C. Injury-reducing effect of seat belts on rear seat passengers. Gothenburg: Volvo AB and Swedish Road Safety Office (TSV), undated.

12 Turbell T. Child restraint systems-frontal impact performance. Linköping: National Road and Traffic Research Institute, 1974. (Report No 36A.)

${ }^{13}$ Ryhammar L, Bergland $\mathrm{CW}$. Children and instruction in road safety. Uppsala : Department of Education, 1980. (Report on Education No 8.)

14 Bäckström K. In: Berfenstam R, Gustafsson LH, Petersson O, eds. Prevention of accidents in children. Uppsala: Department of Social Medicine, University Hospital, 1977.

15 Schioldborg P. An evaluation of the 'children's traffic club' in Norway. Oslo: University of Oslo, Institute of Psychology, 1974. (In Norwegian with English summary.)

16 Vinjé M. Children as pedestrians: abilities and limitations. Gröningen: Traffic Research Centre, University of Gröningen, 1980. (Report No VK 79-03.)

17 Institute for Road Safety Research (SWOV). The pedestrian as a road user. Voorburg: SWOV, 1977.

18 Bérard-Andersen K. Children traffic and us adults. Oslo: Institute of Transport Economics, 1980. (In Norwegian with mimeographed English summary.)

19 Bjerrum L, Iversen L. Traffic mortality among Danish children. Ugeskr Loeg 1979;141:1791-7. (In Danish.)

${ }^{20}$ Office of Population Censuses and Surveys. Occupational mortality 1970-72. England and Wales. London: HMSO, 1978. (Series DS No 1.)

(Accepted 21 fune 1982)

If conventional treatment fails have "alternative" therapies a place in the treatment of pollen allergies?

Acupuncture may help patients with hay fever or asthma whose symptoms are worst in the hay fever season, though this does not necessarily mean it is due to pollen allergy. About $20 \%$ of patients with hay fever may be helped, as may $30 \%$ of patients with asthma. The relief, if it occurs, is quite reasonable (patients say two-thirds better) but only rarely complete. If the patient is taking steroids continuously the chances of helping a patient are microscopic; if he is taking sodium cromoglycate (Intal) the chances of success are reduced; while the more traditional type of drugs do not affect acupuncture at all. One can usually tell at the first or second consultation if acupuncture will help or not. If acupuncture does help about four treatments are required the first year, and one or two treatments subsequent years. If the pollen count is low, as happens some years, pep-up treatments may not be required. The best type of patient in whom to try acupuncture is one who reacts badly to antihistamines or other drugs with drowsiness, headaches, etc. In this relatively small group of patients acupuncture may be the answer.-FELIX MANN, specialist in acupuncture, London. 